\title{
The development of a spinal injuries unit in Armenia
}

\author{
D C Burke FACRM FRACP FRACS, ${ }^{1}$ D Brown FRACP FACRM,${ }^{2}$ V Hill FACRM,${ }^{3}$ \\ $\mathrm{K}$ Balian $\mathrm{MD},{ }^{4} \mathrm{~A}$ Araratian $\mathrm{MD},{ }^{4} \mathrm{C}$ Vartanian $\mathrm{MD}^{+}$ \\ ${ }^{\prime}$ Austin Hospital Royal Talbot Rehabilitation Centre, Melbourne, Victoria, Australia; \\ ${ }^{2}$ Spinal Injuries Unit, Austin Hospital, Melbourne, Victoria, Australia; ${ }^{3}$ Spinal Injuries \\ Unit, Princess Alexandra Hospital, Wooloongabba, Brisbane, Queensland, Australia; \\ ${ }^{+}$Armenian Spinal Unit, Yerevan, Armenia.
}

A severe earthquake in December 1988 in Armenia, resulted in a large number of spinal cord injuries. A rehabilitation facility was urgently established in Yerevan by the Red Cross with volunteers from various countries outside the then Soviet Union.

A programme of training of Armenian cioctors, nurses and therapists was established, and a new purpose built spinal unit planned. The new unit was opened in August 1992 and should serve as a model for similar units throughout the Commonwealth of Independent States.

Keywords: earthquake; spinal cord injuries; Armenian spinal unit.

\section{Introduction}

A severe earthquake on 7 December 1988 in Armenia killed at least 25,000 people, injured more than 150,000 , and left 500,000 people homeless. Amongst those injured were a large number with spinal cord injuries. It became apparent that the specialised facilities required to deal with the spinal cord injured were grossly inadequate. The Armenian government and the Soviet Red Cross appealed to the League of Red Cross and Red Crescent Societies for assistance and it was decided to set up a spinal cord unit in Yerevan, the Armenian capital.

This paper describes the first 12 months of establishing a treatment programme and initiating a training programme for Armenian staff. It will briefly describe the status of the new unit today, but a further paper is foreshadowed which will describe in detail the training programme and opening of the unit.

\section{The response of Red Cross}

The League (now the International Federation) of Red Cross and Red Crescent Societies based in Geneva appealed to its member societies to send nurses, physiotherapists and doctors to form a rehabili- tation team. Two of the authors were approached to be team leader and to help establish the unit. One of the doctors (1) arrived in Yerevan by the end of February 1989 to lead the team for the first 3 months, followed by the second doctor (2) for 3 months. The third author (3) led the team for 3 months until the end of 1989, when it was decided to continue the work beyond the original planned 6 months. The initial team of nurses and physiotherapists were recruited from Ireland, France, Germany, Japan, Canada and United States. An airlift of equipment was arranged from Geneva.

The team commenced working in the Scientific Research Institute of Physiotherapy in the first week of March when the team had been assembled and some equipment had arrived. In June, two occupational therapists and an orthotist joined the team. The composition of the team changed over the reported period as further staff were recruited from Australia and the above and other countries, as most staff were on 6-month contracts.

\section{The patients}

During the first 10 months 42 victims of the earthquake were admitted to the unit. All 
were paraplegic. Fifteen patients with minor paralysis were rehabilitated in a short period of time and discharged. Twenty-seven had severe paralysis. For the majority, initial treatment had been laminectomy, which in a number of cases had led to further destabilisation of the spine causing gross deformity. It was possible for a number of these patients to have spinal surgery to correct the deformity performed in Yerevan by visiting American surgeons, but the deformity was so severe in 2 patients that they had to be transferred to Germany and the USA respectively for surgery. Twenty-six patients were admitted with grade 3-4 pressure sores, 2 of whom eventually died from severe sepsis present on admission to the unit.

Thirty other spinal cord injured patients were also admitted in this period. These had become paralysed through the usual causes such as road traffic accidents, falls etc, 10 before the earthquake and 20 after.

\section{Establishment of the unit}

The unit was housed in a renovated 24-bed ward. All equipment, including beds and mattresses, wheelchairs and cushions, drugs, dressings, and urinary equipment had to be supplied from other countries.

An area in the basement of the hospital was allocated as a physiotherapy gymnasium. Arrangements were made to have some equipment flown in from outside the Soviet Union and for other equipment to be manufactured locally.

After the initial phase of management, which was predominantly concerned with treating complications such as pressure sores, and included the surgical repair of a number of the pressure sores by visiting American surgeons, a more active rehabilitation phase was introduced. Because of the low level of injury in many of these patients there was a major need for orthoses for gait training. Various improvisations were used for some months until it was possible to establish an orthotics department 9 months after the earthquake.

Other difficulties with the fledgling rehabilitation programme included the psychological reaction, with most of the patients and their relatives coming to the centre expecting cure, as before the establishment of the unit the contemporary treatment of rehabilitation of spinal cord injuries was unknown in the Soviet Union. The philosophy of rehabilitation had to be explained to the patients and the Armenian staff at the hospital with the help of interpreters who were university students specially recruited for the purpose.

Additionally, all patients had suffered severe psychological trauma from the earthquake-from deaths of close family and friends, loss of homes and jobs, loss of income, as well as personal injury to spine and spinal cord, and severe crush injury.

Once the patients were ready to be discharged back into the community major difficulties were encountered with housing, as most of the patients had lost their homes in the earthquake. The massive task of building both temporary and permanent housing for such a large number of people, quite apart from the need for specially adapted housing for the disabled, was a major problem in the first year after the disaster, and has continued to be so. There was little understanding of the needs of disabled people on return to the community, not only with regard to housing but also with return to school or work. The special needs for access by disabled people in the community were concepts unknown in the Soviet Union.

A visiting programme was established. It had two aims. One was to assist with finding housing and advising the authorities of building standards for disabled access. The other was a visiting nurse service. To these was added an outpatient review programme from the eighth month of the unit's existence.

\section{Planning for the future}

It was apparent from the time of the establishment of the unit in March 1989 that there was an obvious need for a permanently established spinal unit in Armenia. To accomplish this would require training of local health professionals and preferably the building of a new purpose built unit. 
The training of Armenian staff began soon after the establishment of the unit. A lack of interest amongst trained nurses at the hospital led to a decision by the Minister of Health to allocate a group of 20 new nursing graduates to the unit, and these young people began an apprenticeship type of learning programme, working alongside the Red Cross nurses on the same day and night shifts.

Within a few weeks of opening the unit a young doctor (4) was seconded to work alongside the first of the team leaders. This doctor has worked with all of the subsequent team leaders and in 1990/91 spent 5 months receiving more advanced training in the Spinal Injuries Unit of the Austin Hospital, Melbourne. Two other young doctors, (5) and (6), were recruited in 1989 and 1990 and have similarly received on the job training. They too have received more advanced training for 6 months each, in Germany and the Netherlands. A fourth doctor, with a background in internal medicine, joined the group in 1992.

A group of young specialist surgeons was also introduced to the management of spinal injury patients by working part-time alongside the team leaders. It was considered important that a neurosurgeon, urologist, orthopaedic surgeon and plastic surgeon should also have the opportunity of spending some time in established units outside the former Soviet Union for more advanced training in the special surgical techniques required in the contemporary management of spinal cord injuries.

Physiotherapists were initially more difficult to recruit, though their interest in learning the rehabilitation techniques from the Red Cross therapists was evident. The difficulties in training Armenians to become occupational therapists and social workers was even greater because there were no equivalents to these disciplines in the Soviet Union.

The training programme has continued under subsequent team leaders, and has been progressively taken over by the Armenian doctors and the other staff who have been trained by the expatriates. Thirty-four Armenian nurses now work on the unit, including the head nurse. Twelve
Armenians have been trained as rehabilitation therapists, combining training in rehabilitation physiotherapy and in occupational therapy. There are also three trainees in orthotics under the supervision of a German orthotist.

As the Institute of Physiotherapy was considered to be inappropriate as a permanent unit, plans for a new purpose built unit were developed with the assistance of a group of German architects with advice from Professor Paeslack from Heidelberg, Germany. An 8-bed acute care unit was incorporated in the new 116-bed rehabilitation unit. Half of the beds in the unit are for medical rehabilitation, the remainder for professional (vocational) rehabilitation. The centre opened on 28 August 1992 and further training of Armenian staff, particularly in the acute unit, will need to continue with the assistance of expatriate staff over the next 12 months. Details of the training of Armenian staff and the opening of the new unit will be the subject of a further paper.

\section{Outcome of treatment programme}

At the end of December 1989, of the 42 patients admitted to the unit as a result of injuries sustained in the earthquake, 40 were still alive. It is understood that all have survived to the present. Twenty-one patients regained normal bladder function, 9 were catheter free, 8 were on intermittent self catheterisation, and 2 had suprapubic catheters. Twelve of the patients were walking without aids, 21 walking with aids, and only 7 were confined to wheelchairs.

\section{Discussion}

Through the initiative of the Red Cross a spinal unit was established at short notice in a country which had no rehabilitation facilities, to help the victims of a major natural disaster. In the 3 months between the earthquake and the opening of the unit a large number of severely paralysed patients acquired preventable complications, treatment of which formed the bulk of the work 
undertaken during the first 3 to 6 months of the unit. Also, an unknown but possibly large number died without getting to the unit.

The major lesson to be learned from this hastily established unit is that every country needs an adequately equipped and staffed specialist spinal unit for the treatment and rehabilitation of patients sustaining the usual random spinal cord injuries. Such a unit would have the ability to immediately expand its services in the event of a natural disaster or war, to cope with a sudden influx of many new patients. Valuable resources would not be consumed in the treatment of preventable complications, and rehabilitation of patients would not be delayed as it was in Armenia. Another important lesson is that death and injury from earthquakes can be minimised by safe building practices. The small number of deaths from an almost identical earthquake in San Francisco in 1990 compared to Armenia where over 25,000 died in poorly constructed high rise buildings, illustrates graphically the value of preventative measures.

The International Medical Society of
Paraplegia (IMSOP) has much to offer the young doctors who will be the leaders of the new spinal unit in Armenia, by giving opportunities to them and their staff to visit other established units and by visiting the centre to lecture and teach. It is hoped that this centre will act as a model for similar centres to be developed in other countries of the Commonwealth of Independent States. We note also that the International Federation of Red Cross and Red Crescent Societies is developing a spinal cord unit in Bucharest, the capital of Romania. Nurses, physiotherapists and occupational therapists are urgently needed to establish training programmes for local staff. We urge members of IMSOP to encourage experienced staff to help this worthy humanitarian project also, as well as encouraging staff to volunteer to work in Armenia during 1992 and 1993 to complete the training programme.

A new spinal unit has emerged in 3 years from the ashes of a terrible natural disaster. It has been a remarkable, cooperative effort by hundreds of people from all over the world. 